\title{
建筑工程施工的精细化施工管理研究
}

\author{
戴荣华* \\ 江苏省苏中建设集团股份有限公司，江苏 226600
}

摘 要: 在经济快速发展的形势下, 建筑行业也迎来好的发展前景, 工程建设的规模、数量等都呈现出增长的趋势。在快速发 展的过程中不可避免出现问题, 施工管理依旧不是十分理想, 建筑工程施工质量不达标的情况时有发生, 对于建筑施工企业经济效 益以及社会效益的实现是不利的。当前, 建筑市场竞争激烈, 施工企业若要提高竞争中的自身实力, 就必须做好施工的管理, 运用 精细化的管理方法全面推进建筑工程的施工建设，为建筑行业的持续稳定发展奠定良好的基础。

关键词：建筑工程；施工；精细化施工管理

\section{Research on Fine Construction Management of Construction Engineering}

\author{
Rong-Hua Dai* \\ Jiangsu Suzhou Construction Group Co., Ltd., Nantong 226600, Jiangsu, China
}

\begin{abstract}
Under the situation of rapid economic development, the construction industry also ushered in good development prospects; and the scale and number of engineering constructions are showing an increasing trend. Problems inevitably arise in the process of rapid development, and construction management is still not very ideal. The quality of construction projects does not meet the standards from time to time, which is unfavorable for the realization of economic and social benefits of construction enterprises. At present, the competition in the construction market is fierce. If construction companies want to improve their own strength in the competition, they must do a good job of construction management and use refined management methods to comprehensively promote the construction of projects, and lay a good foundation for the sustainable and stable development of the construction industry basis.
\end{abstract}

Keywords: Construction engineering; construction; fine construction management

一、前言

精细化管理是一种全新的管理理念, 其以常规化管理为基础, 精细化管理中涉及社会分工、服务质量等内容, 其对传统的常规 化管理理念、模式进行完善和升级, 能够使传统管理方式的不足得到改善, 减少管理成本, 并提高管理质量。在建筑工程施工中应 用精细化的施工管理方法，对于工程质量水平、施工团队协作、企业经济以及社会效益的实现有着重要的促进作用。

\section{二、精细化管理概述}

建筑工程的精细化管理是一种管理理念, 可以将其作为一种个性化管理。在工程建设中要实现精细化管理, 工作人员在作业过 程中要科学的分工，细化工作内容，并提高建筑工程质量的精细化管理。

就目前建筑工程行业而言, 精细化管理就是要实现精细化、规范化、个性化。工程建设过程中应用精细化管理理念, 能够与现 代化建筑企业的发展需要相适应, 使整个建筑工程施工的质量达到标准 ${ }^{[1]}$, 帮助企业创造良好的经济效益。在精细化管理过程中, 需要明确建筑企业的发展目标，施工过程中依据相应目标采取有效措施处理。

建筑工程精细化管理时, 需要每一位工作人员积极投人并相互配合, 保证精细化管理工作效果的实现。建筑工程施工过程中, 相关的作业需要依据标准规范严格进行，利用精细化管理的模式使建筑企业竞争力得到提升。

\section{三、建筑工程施工精细化管理的原则}

(一) 规范化

建筑工程施工中, 精细化管理要落实到实处、达到理想的效果, 在实际管理过程中必须要依照规范化的原则开展工作, 使管理 过程更加规范、严谨, 避免施工过程中违规违纪行为的出现, 使每一个施工环节的质量都能够达标, 最大程度地发挥精细化管理的 作用价值。

管理工作开展过程中, 积极落实规范性原则, 避免出现管理误差, 提高管理的效率, 也使管理决策科学合理, 提高工程资源的 利用率。强化工程施工建设的安全性, 减少施工过程中安全隐患的出现，使工程建设、管理高效、有序推进 ${ }^{[2]}$

(二) 服务性

建筑工程施工的精细化施工管理还具有服务性的特点, 为使其服务性得到体现, 在管理过程中, 工作人员需要依据服务性原 则开展工作, 保证工程施工建设操作有便利的条件, 使施工管理过程中呈现出的风险、隐患等妥善处理, 促进建筑工程施工有序推

*通讯作者：戴荣华，1982年03月，男，汉族，江苏东台人，现任江苏省苏中建设集团股份有限公司助工，本科。研究方向： 建筑安全管理。 
进, 避免工程出现质量、安全、成本等问题。

精细化管理时, 对于各单位提出的合理要求要尽可能地满足, 对于质量、成本、进度等方面的要求要科学控制, 保证落实效

果。对于安全性的要求, 依据精细化管理理念对施工过程中的安全隐患进行有效处理, 尽最大努力处理安全隐患, 提高工程施工建 设的安全性。

（三）细节化

精细化管理其实就是要对工程施工进行细致化的管理, 施工管理中依据细节化的原则, 处理好工程中每一个环节、细节的工 作, 使精细化管理的效果得到提高, 同时避免工程建设中出现质量问题, 提高工程成本的利用率。工程建设具有一定的复杂性, 施 工的内容也比较多, 操作步骤烦琐 ${ }^{[3]}$, 不管施工中的哪一个细节出现问题, 都可能影响工程施工的质量、安全以及成本, 因此细节 管理就面临着较高的要求。为实现细节管理的要求, 管理人员要结合工程现状对精细化管理进行科学的规划, 有效管理施工细节, 提高管理效果。

\section{四、建筑工程施工精细化施工管理现状}

(一) 监理工作存在滞后性

建筑工程中, 要提高工程施工建设的质量效果, 施工人员的施工技术、工程监督管理都发挥着巨大的作用。其中工程监理是对 整个施工建设过程进行监督、控制，为工程质量的实现以及建筑企业经济效益的实现提供坚实的保障。但在实际的工程建设中，大 多数施工建设单位的监理意识不足, 自然影响监理工作开展, 致使工程无法按期完工, 超过规定的交付时间 ${ }^{[4]}$, 严重制约建筑企业 经济效益以及社会效益的实现。虽然近些年来监理工作的法律法规等逐步完善, 但是监理人才、水平等不足依旧是限制监理工作效 果实现的重要因素, 导致工程安全、质量隐患依旧存在。

(二) 施工技术水平不高

经济的发展带动建筑行业的进步, 市场竞争也日渐激烈, 为使建筑工程行业在激烈的市场竞争中获取优势地位, 施工技术的提 升是极为必要和重要的, 同时加强建筑工程的监督管理。但是就目前我国市场发展的情况而言, 建筑工程施工建设中依旧存在不少 问题, 施工技术水平不高, 材料、设备等无法满足社会发展需要, 使得工程施工效率受到限制, 工程无法在规定时间内完成, 只能 延期。

(三) 施工队伍整体素质有待提升

当前大部分建筑施工企业的人员水平不高, 专业技能以及素质等偏低, 由于建筑工地的工作十分辛苦、存在危险性, 施工人员 一般是农民工, 其文化水平偏低, 年龄普通比较高, 没有接受过专业的知识技能培训, 对新技术、新工艺等了解不足, 给建筑工程 的管理增加难度。

施工人员上岗前没有经过专业的岗前培训, 缺少相关证件 ${ }^{[5]}$ 。加之施工单位对于工作人员的技能培训不到位, 使得施工人员自 已也不关注技能提升, 这对于建筑工程的建设以及建筑企业的发展极为不利。

\section{五、建筑工程施工精细化施工管理的策略}

（一）树立精细化的管理意识

建筑企业需要高度关注精细化管理, 管理人员要树立精细化的管理意识, 明确人员责任, 施工中结合现场实际实现实时的监督 管理，保证工程施工建设中的问题得到及时妥善的处理，避免工程施工建设中出现质量问题。

工程建设有很强的复杂性, 工程项目比较多, 涉及的施工企业也比较多, 施工技术、工艺等多样化, 这就需要各个施工单位之 间相互交流，做好协调 ${ }^{[6]}$ ，形成良好的合作关系，保证工程建设有序推进，维护工程的整体施工效果。

建筑企业要有一定的规则意识和施工管理能力, 全面提升施工效率, 保证工程质量不受影响, 促使建筑企业健康持续进步。为 此建筑企业要完善组织结构，优化施工管理水平，探索新的技术工艺为施工建设提供保障。

(二) 精细化编制施工方案

在建筑工程施工的精细化管理过程中, 需要精细化处理组织方案, 做好事前准备工作, 为之后的工程施工管理提供保障。精细 化施工管理时, 要科学研究施工组织方案的可行性。

就内容而言, 建筑工程整体规划方案的设计就是要对拟建工程项目与已有资源利用间的关系进行处理, 对整体规划的原则进行 把握，科学的布局工程项目，明确工程建设的规模。

就设计对象而言, 规划设计片区范围内的基础设施以及施工现场的要素, 对现场进行精细化管理, 完善管理制度, 使建筑工程 的精细化水平得到提升。

（三）全面加强现场施工监管

建筑工程现场的施工监管过程中, 在施工前要对施工现场进行全面的勘察, 尤其是工程所在地的地质情况, 依据施工现场的环 境制定方案。同时全面的对工程规模以及工程量进行分析, 评估工程施工建设的难度, 依据测算的结果完善进度表。如今建筑行业 迅猛发展，政府及相关部门要完善相关的法律法规，使施工现场更加安全。

完善精细化管理制度, 对工程机构的责任进行明确, 科学化分工, 由项目经理带头, 工程师、安全总监等对施工现场的具体情 况进行调度 ${ }^{[7]}$, 并严格负责, 加强财务部门、管理部门以及综合部门间的合作。明确组织机构人员的职责, 对工程任务细化分解, 依据工程项目实际科学选择施工设备、技术，保证工程按时、安全完工。 
施工过程中进行精细化管理还需要对合同内容进行管理, 以此为依据协调好工程的施工进度计划、方案等, 围绕施工现场实际 调整计划与方案。制定施工方案时依据总工期, 综合考虑施工技术、工艺等, 保证施工计划的合理性, 使工程施工的质量以及进度 效果顺利提升，如图1。

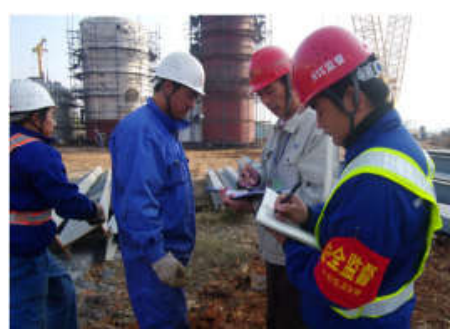

图1 施工现场监管

(四) 发挥科学技术优势

当前网络信息化技术水平逐渐提高, 并对人们的生活、工作等带来变化, 使其更加便利。在建筑工程施工精细化管理过程中也 需要发挥信息技术、科学技术优势, 使精细化管理的效率以及水平得到提高。发挥信息技术优势建立精细化管理的信息系统, 对施 工现场实时监管 (如图2), 能够第一时间获得施工数据, 以此对建筑工程的施工情况进行分析, 及时发现其中存在的安全、质量 隐患，并利用远程设备控制施工现场，全面提高施工过程的安全性、规范性。

监管部门人员利用网络查询等功能, 通过网络及时查找施工中出现的问题, 减少问题对工程建设造成的损失, 并减轻管理人员 的压力和工作量, 全面深人的开展精细化管理, 提高管理效果。

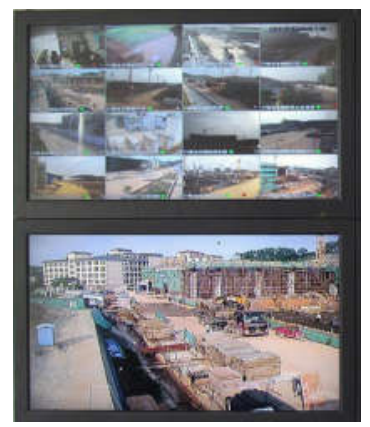

图2 施工现场实时监管

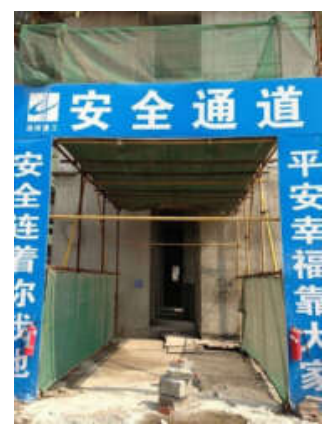

图3 施工现场安全通道

（五）推进安全精细化管理

对于建筑工程而言, 采取一系列有效管理措施的目的就是减少工程施工建设中的意外, 管理过程中要将人的管理放在重要位置 上, 随时关注施工人员的情况, 遇到恶劣天气等要及时调整工程的施工, 保证工程施工顺利推进。结合工程建设的实际情况建立安 全施工体系 ${ }^{[8]}$, 让施工现场的所有人都认识到安全施工的重要性，并且在操作中规范自身行为，严格按照相关标准施工建设。

在进行具体的施工步骤时, 要有完善的施工计划, 划分不同的建设区域, 科学放置施工材料, 保证施工现场的清洁、干燥, 对 于不同类型的施工材料需要做好标识, 施工现场人员必须要佩戴安全帽, 设置安全通道, 如图 3 。对于不同工种的施工人员, 在操 作时要有明确的标准, 避免操作失误出现意外伤亡。

(六) 施工成本的精细化管理

在施工中要对工程总成本进行科学控制，使建筑企业能够获得良好的效益。

1. 投标环节全面客观评估项目，对投标总价进行确定

施工过程中对投标数据反复核对, 更好地把握工程质量、成本以及进度, 特别是工程变更。如果工程要变更, 需要参建方讨论 之后才能够开展, 避免耗时太多对工程进度造成影响。项目经理依据施工图纸、土石方配置以及材料等核查现场情况, 做好事前的 规划。一旦施工技术方案出现变化，要选择最为先进、节约的方案，控制好工程量变更。

2. 科学管理材料成本

在工程建设中, 材料成本要占到总成本的 $65 \%$ 左右, 并且材料成本所占的比重呈现出逐渐增多的趋势。可以看出, 材料的选择 是否经济合理将对工程的造成产生直接性的影响。为此建筑企业可以通过理论计算、实验等方法对工程建设中材料的净用量以及损 耗量进行计算，明确定额指标。定额制定过程中要将先进的施工技术经验纳人其中，分析施工工艺与环境，尽最大可能减少成本。 同时对于边角料、库存等做好保管，防止材料损失浪费。

3. 人工成本也是极为重要的消耗

要对管理人员科学合理的配置, 依据施工过程中的劳动量对用工人员进行准确的计算, 并制定完善的成本考核制度, 使考核工 作更加科学有序。 
在建筑工程项目运行中, 日常的经营、市场的推广以及融资等都是需要进行管理的成本。对这些成本进行管理时, 要通过历史 数据、编制年度预算的方式进行。并结合未来年度工程投资的总体情况估算其他费用。

\section{六、结束语}

总而言之, 精细化施工管理在建筑工程施工中起到极为重要的作用, 必须要提高对精细化施工管理的重视程度, 树立精细化的 施工管理意识, 认识精细化施工管理对建筑工程施工的重要性, 完善相关的管理制度与流程, 保证工程建设项目整体效益的顺利实 现。同时做好工程施工的安全以及成本等管理控制工作, 将安全隐患消灭在萌芽中, 加强施工人员的教育培训, 强化其专业知识技 能，总结管理经验与不足，从可持续发展的角度推动建筑行业的稳定进步。

\section{参考文献:}

[1]顾小进.精细化管理在建筑工程施工管理中的应用 [J].建材与装饰, 2019(30):142-143.

[2]吴云.分析精细化管理在建筑工程管理中的应用 [J].建材与装饰, 2019(29):184-185.

[3]张永胜,张琪.建筑工程管理的现代化和精细化研究[J].科技创新与应用, 2019(27):189-190.

[4]陈龙.精细化管理在建筑工程施工安全管理中的应用 [J].安徽建筑, 2019,26(09):264-265.

[5]邓娣.浅析建筑工程施工管理中精细化管理的应用 [J].建材与装饰, 2019(25):166-167.

[6]朱祝庆.精细化管理在建筑工程施工管理中的应用 [J].住宅与房地产, 2019(22):136.

[7]邹方华,孙少华,翟慎孟.浅析如何强化建筑工程施工的精细化施工管理 [J].居业, 2019(07):172-173.

[8]刘成伟.精细化管理模式在建筑工程施工中的应用研究 [J].中外建筑, 2019(07):200-201. 